\title{
Numerical investigation of solar collectors as a potential source for sintering of $\mathrm{ZrB}_{2}$
}

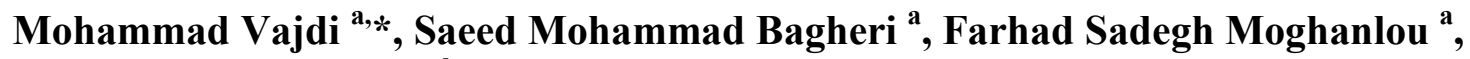 \\ Amin Shams Khorrami ${ }^{\text {b }}$
}

${ }^{a}$ Department of Mechanical Engineering, University of Mohaghegh Ardabili, Ardabil, Iran

${ }^{b}$ Mechanical Engineering Department Alumni, York University, Toronto, ON, Canada

\begin{abstract}
A B S T R A C T
Sintering of ceramics is an energy-consuming process that needs high temperatures, therefore, in the present work; solar energy is used to produce high temperatures for the sintering aim of different materials. Solar energy concentrators increase the intensity of incident energy to the receiver provides high temperatures. Ultrahigh-temperature ceramics (UHTCs) due to their high melting point can also be a good alternative for receiver materials. In the present work, $\mathrm{ZrB}_{2}$ is introduced as an alternative material for solar receivers which can withstand high temperatures of sintering. The governing equations, including heat radiation and conduction ones are solved numerically using the finite element method. Transient heat transfer in the concentrator-collector system is investigated to check the feasibility of high temperatures needs for sintering at the receiver. The highest temperature of $1680^{\circ} \mathrm{C}$ was achieved after 15 minutes at the focal point of the concentrator when the solar heat flux of $6.86 \mathrm{w} / \mathrm{mm}^{2}$ used for the location of the city of Ardabil in Iran. The obtained temperature can be used to sintering of some groups of materials.
\end{abstract}

(C) 2021 The Authors. Published by Synsint Research Group.

\section{KEYWORDS}

Sintering
Solar energy
$\mathrm{ZrB}_{2}$
Numerical method
Solar receiver

Sintering

Solar energy

$\mathrm{ZrB}_{2}$

Solar receiver

\section{Abbreviation}

\begin{tabular}{|c|c|c|c|c|c|}
\hline \multicolumn{2}{|c|}{ Symbols } & \multirow{2}{*}{$\begin{array}{l}\mathrm{Q}_{\mathrm{T}} \\
\mathrm{T}\end{array}$} & \multirow{2}{*}{$\begin{array}{l}\text { Total heat transfer }(\mathrm{W}) \\
\text { Temperature }(\mathrm{K})\end{array}$} & \multicolumn{2}{|c|}{ Subscripts } \\
\hline $\mathrm{C}_{\mathrm{p}}$ & Heat capacity (J/kg.K) & & & $\mathrm{a}$ & Absorbing surface \\
\hline $\mathrm{D}$ & Hieght of reciever (m) & $\mathrm{T}_{\mathrm{a}}$ & Absorption surface temperature $(\mathrm{K})$ & cond & Conduction \\
\hline $\mathrm{H}$ & Diameter of reciever $(\mathrm{m})$ & $\mathrm{T}_{\mathrm{e}}$ & Emission surface temperature $(\mathrm{K})$ & conv & Convection \\
\hline M & Mass (kg) & $\mathrm{T}_{\mathrm{f}}$ & Final temperature $(\mathrm{K})$ & e & Emission \\
\hline$\dot{\mathrm{q}}$ & Heat generation & $\mathrm{T}_{\mathrm{i}}$ & Initial temperature $(\mathrm{K})$ & $\mathrm{f}$ & final \\
\hline $\mathrm{Q}_{\text {cond }}$ & Conduction Heat transfer (W) & \multicolumn{2}{|c|}{ Greek letters } & $\mathrm{i}$ & initial \\
\hline $\mathrm{Q}_{\text {conv }}$ & Convection heat transfer (W) & $\alpha$ & Thermal diffusivity $\left(\mathrm{m}^{2} / \mathrm{s}\right)$ & $\mathrm{r}$ & radiation \\
\hline$\dot{\mathrm{q}}_{\mathrm{r}}$ & Radiation heat flux $\left(\mathrm{W} / \mathrm{m}^{2}\right)$ & $\varepsilon$ & Surface emissivity & $\mathrm{T}$ & Total \\
\hline $\mathrm{Q}_{\mathrm{r}}$ & Radiation heat transfer (W) & $\sigma$ & Stefan-Boltzmann constant & & \\
\hline $\mathrm{t}$ & Time (s) & & & & \\
\hline
\end{tabular}

* Corresponding author. E-mail address: vajdi@uma.ac.ir (M. Vajdi)

Received 1 March 2021; Received in revised form 7 May 2021; Accepted 8 May 2021.

Peer review under responsibility of Synsint Research Group. This is an open access article under the CC BY license (https://creativecommons.org/licenses/by/4.0/ https://doi.org/ 10.53063/synsint.2021.128 


\section{Introduction}

Any energy-saving program contributes to sustainable development, higher productivity, revenue creation, expense reduction, and improvement of the environment, especially using renewable energies as the main source of power such as biogas, wind, and solar systems [1]. Concerns about the environmental issues about the pollution of the fossil fuels used in engines, power plants, and manufacturing units, need to employ environment-friendly and clean energy resources as well as enhancing the performance of the working systems by active or passive methods [2-6]. Solar energy utilization, as $\mathrm{CO}_{2}$ emission-free energy, has drawn attention from researchers all over the world $[7,8]$. Generating power from solar energy is a valuable technology, which makes the extensive utilization of solar energy $[9,10]$ that can be categorized into three types of concentrators, dish, and tower system. Via its merits such as higher concentration ratio and system efficiency $[11,12]$, the dish/Stirling system attracts the most attention in the solar thermal power generation field. On the other hand, solar furnaces, which consist of concentrator and receiver, are a special design for absorbing high irradiance. They can produce high temperatures which can be used in different fields such as material processing [13,14], and sintering of UHTCs which consume a lot of energy to consolidate the ceramic powders [15]. The critical part of the solar dish system is the receiver, which absorbs reflected solar energy from the concentrator and transfers it to the using system that includes both thermal and optical effects. The efficiency of solar thermal conversion directly can be affected by optical performance in the first step. To enhance optical performance through structural optimization, there are great efforts [16-19]. There are two essential approaches in the optical analysis [20], the first one is using experimental formulas that are simple to compute and are used to estimate the optical efficiency of the receiver [21-25]. Although this method is uncomplicated, it cannot result in true accurate design geometry of the receiver. The more reliable and accurate model to achieve optimal efficiency and radiation flux distribution and more optical information is Monte Carlo Ray Tracing Method (MCRTM) [26-30]. According to diverse studies about the concentrator system, optical analysis via MCRTM has three main classifications. Involving the effect of concentrator on optical efficiency or radiation flux distribution [28], the impact of the receiver on optical performance [16,31], and the influence of both receiver and concentrator on the optical performance of the system [29]. Rosas et al. [26] investigated various optical arrangements by considering the maximum peak concentration, cost-effectiveness, and obtained the best distribution. León et al. [32] examined the series of Fresnel Lens dealing with a multi-objective optimization process to concentrate solar energy to get $1000{ }^{\circ} \mathrm{C}$ on the receptor area. Abbas et al. [27] utilized circular-cylindrical and parabolic-cylindrical mirrors with divers reference positions to analyze and optimize the performance of Fresnel arrays and examined a mirror design to achieve constant radiation on the receiver. Qiu et al. [28] studied the optical performance of a linear Fresnel solar reflector considering the effect of slop error, time and location by adding molten salt. Shuai et al. [33] compared six classical cavity geometry to achieve radiation flux distribution and presented an upside-down pear cavity, a new geometry, which demonstrated spatial uniformity better than earlier cavities. Likewise, Xie et al. [34] concluded optimal structural design by accurate thermal analysis with comparing concentration ratio and optical efficiency of three different cavity receivers. Recently, some researchers have begun to study the geometrical influences on cavity receivers. Zou et al. [35] demonstrated the thermal performance of the cavity receiver via the effects of geometric factors using a 3D numerical model. Hogan et al. [36] determined that convection heat losses for large apertures are exaggerated. Asselineau et al. [31] applied the strategy of unified MCRTM with stochastic optimization to optimize the geometrical configuration of a receiver with maximum efficiency. Wang et al. [16] experimented two different cylindrical cavity receivers with the convex on the bottom surface for the aim of solving the problem of dead space and enhance the optical efficiency of the cavity receiver. Wang et al. [37] found achievable cavity receiver design by relative homogeneous surface temperature for the cavity wall via inverse design method. Also, there are several studies that investigated thermal and heat transfer of the receiver. Beltran et al. [38] discussed the thermal performance of cavity receivers with a mathematical model by taking into account the errors of the collector, intercept factor, reflected radiation, conduction, and convection heat losses. Wang et al. [39] developed a combined numerical heat transfer model of an impinging receiver and integrated a small-scaled solar dish-Brayton system with a ray-tracing model. Xu et al. [40] designed a high-temperature solar dish receiver where TTBR (tapered tube bundle receiver) absorber emissivity was 0.95 by calculation while TTBR absorptivity is 0.2 via ray-tracing simulation. Senthil and Cheralathan [41] experimented with a receiver prototype welded by five vertical $2.5 \mathrm{~mm}$ thickness mild steel fins with thermal conductivity of $16.27 \mathrm{~W} / \mathrm{m} . \mathrm{K}$ while the emissivity and absorptivity of the receiver surface were 0.15 and 0.85 . As demonstrated, the main factors, which are important in the receiver, are emissivity and absorptivity while the material of the receiver can play an essential role. There is a lack of studies according to use different materials to enhance emissivity and absorptivity. Ceramics are the materials, which attract more attention these days in new studies. Because of the high temperatures generated in solar receivers, ceramics, which are endurable in high temperatures without any change in their shapes and structures, can be a good candidate for receiver's material [42], especially UHTCs with significantly high strength and melting points [43]. Moreover, in high temperatures, UHTCs provide satisfying chemical and physical stability [44]. Zirconium diboride, $\mathrm{ZrB}_{2}$, as a UHTC has low density [45], excellent thermal and mechanical properties such as great melting point (3519 K), great thermal conductivity $(60-120 \mathrm{~W} / \mathrm{m} . \mathrm{K})$, high hardness and elastic modulus (500 GPa) [46-51]. Zirconium diboride provides a good potential to be used in hard working environments like corrosion, impact, wear and high temperatures, thus, it has vast applications in broad fields of engineering. Kinoshita et al. [52] used the radio frequency heated floating-zone method to produce $\mathrm{ZrB}_{2}$ single-crystal and calculated anisotropic thermal conductivity via laser flash method. Vajdi et al. [43] investigated microchannel heat sink made of $\mathrm{ZrB}_{2}$ in high heat flux conditions and evaluated the cooling ability numerically by finite element method. Sadegh Moghanlou et al. [53] simulated the temperature distribution through several diboride-based materials, including $\mathrm{ZrB}_{2}$, via studying heat transfer in cutting tools. Xiang et al. [54] predicted intrinsic lattice thermal transport properties of $\mathrm{ZrB}_{2}$ via analytical simulations and related heat conduction of $\mathrm{ZrB}_{2}$ to its structural properties.

Numerous studies have been performed in different branches of engineering such as heat and mass transfer [55], biomechanics [56], manufacturing [57, 58], energy systems [34], etc. This method provides point by point details of the process and helps to have a better view of 


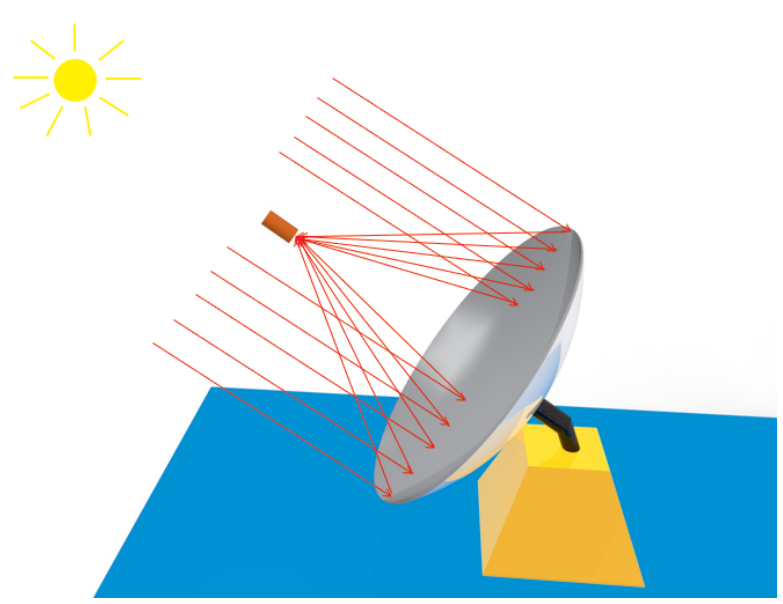

Fig. 1. The schematic of a solar dish and the cylindrical receiver.

the performance of the investigated system and reduced the corresponding costs. To the authors' knowledge, the application of $\mathrm{ZrB}_{2}$ ceramic has never been investigated in receivers of solar furnaces. In the present work, the temperature distribution in the receiver of the solar furnace has been investigated numerically. The irradiance has concentrated by a dish on a receiver made of $\mathrm{ZrB}_{2}$ and the maximum temperature was defined.

\section{Model definition and the geometry}

A parabolic dish concentrator with a cylindrical receiver at the focal point was simulated in the present work. The schematic of the dish and the receiver is shown in Fig. 1 including some ray traces.

First, the solar flux as radiation was reflected from the solar dish and concentrates at the focal point where the cylindrical receiver was located. By adapting the cylinder shape, the concentration ratio for various cavity geometries can be computed as in [33], however, in the present study, the concentration ratio has been computed only at the focal point. Two cases of ideal and real reflectors were considered. In an ideal reflector, all the incoming rays would be focused on the focal point of the paraboloid dish. For such an assumption the dish is
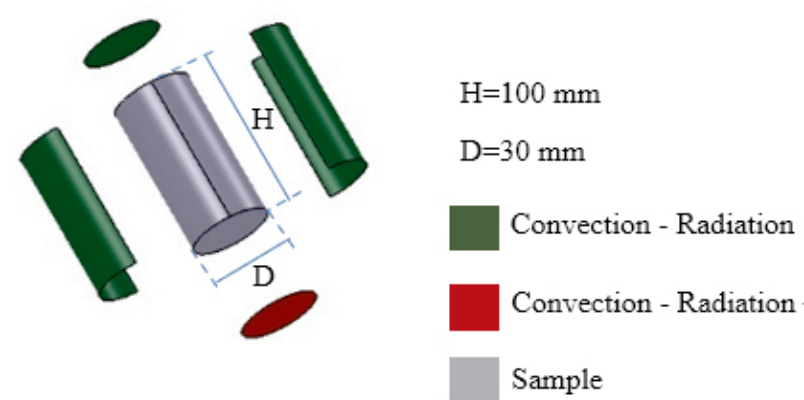

Fig. 2. The receiver geometry and applied boundary conditions.

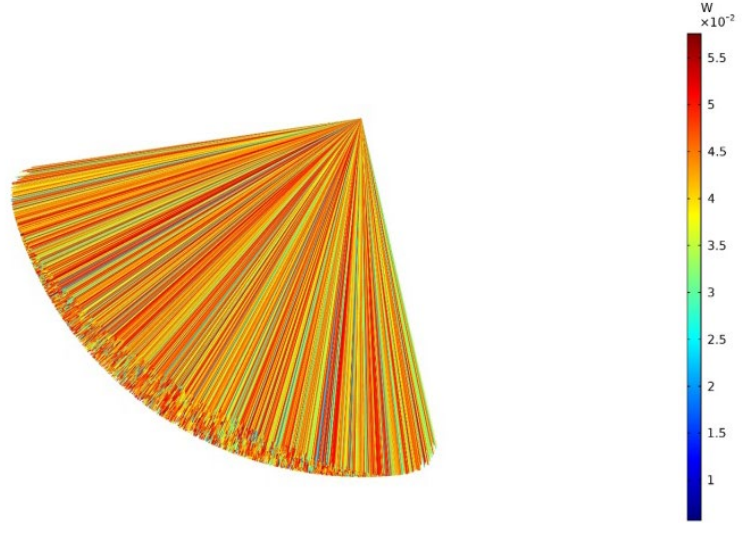

Fig. 3. The ray trajectories from the parabolic collector and concentration in the receiver surface.

supposed to be smooth, and the rays from the sun behaved as planar wave fronts arising out of an infinitely distant point source.

The receiver was a cylinder with a $30 \mathrm{~mm}$ diameter and $100 \mathrm{~mm}$ height. The receiver itself absorbs some of the incoming radiation; however, most of the heat absorption occurs from the bottom of the cylinder, where the reflected radiation is concentrated by the solar dish. In this model the absorption coefficient has been considered 0.8 , meaning that $20 \%$ of the incoming radiation was reflected. The surrounding temperature was $293.15 \mathrm{~K}$ while the convective heat transfer coefficient was assumed to be $5 \mathrm{~W} / \mathrm{m}^{2}$.K. Fig. 2 exhibits the receiver geometry and boundary conditions.

Governing equations in the present work included two parts, one for heat conduction in the receiver, and the second one for radiation heat transfer modeling from the source to the concentrator and receiver.

To calculate the temperature distribution through the receiver, the heat conduction equation in the cylindrical form (Eq. 1) has to be solved.

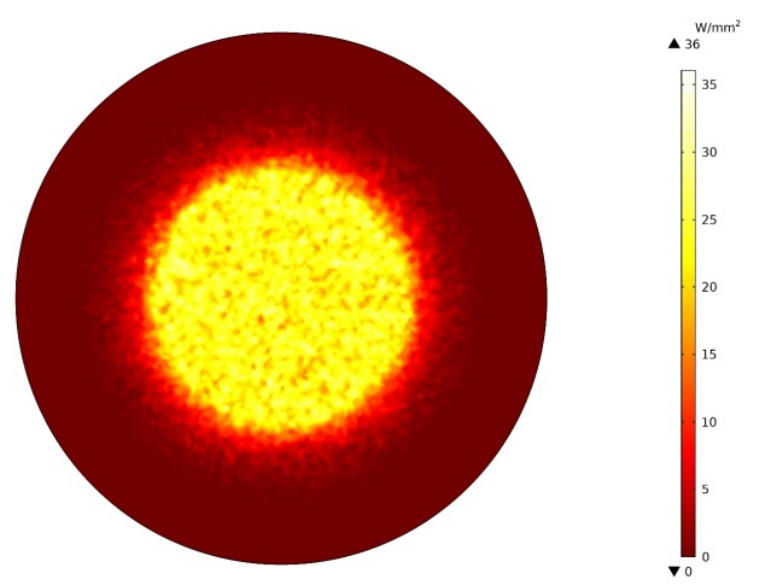

Fig. 4. Heat flux distribution on the bottom surface of the receiver resulted from an ideally smooth non-absorbing paraboloid reflector. 


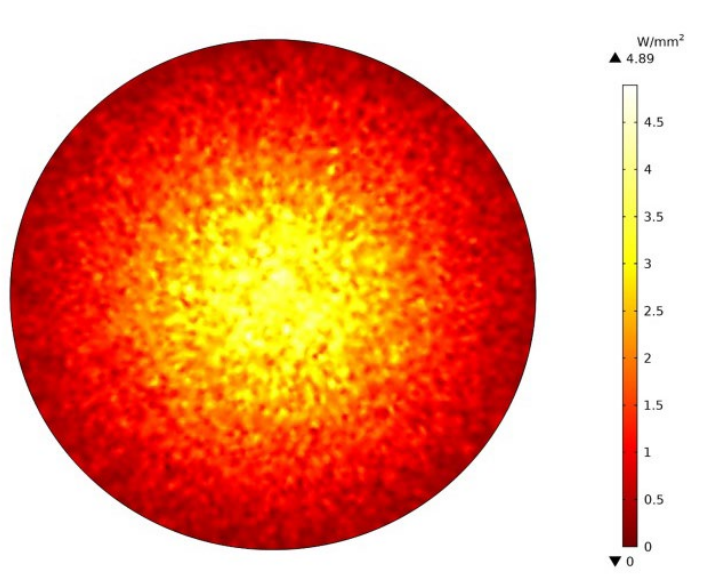

Fig. 5. Heat flux distribution in the focal plane, when the effects of surface roughness, absorption, and solar limb darkening are taken into account.

$\nabla^{2} \mathrm{~T}+\dot{\mathrm{q}}=\frac{1}{\alpha} \frac{\partial \mathrm{T}}{\partial \mathrm{t}}$

where $\mathrm{T}$ represents temperature, $\mathrm{t}$ stands for time. $\alpha$ and $\dot{\mathrm{q}}$ are the thermal diffusivity of the material and any heat generation, respectively.

The radiation main equation is Stefan-Boltzmann law, which demonstrates the radiation heat transfer from a surface to the surroundings as Eq. 2. $\dot{\mathrm{q}}_{\mathrm{r}}=\sigma \varepsilon\left(\mathrm{T}_{\mathrm{e}}^{4}-\mathrm{T}_{\mathrm{a}}^{4}\right)$

where $\dot{\mathrm{q}}_{\mathrm{r}}$ shows the amount of radiation heat transfer per unit of time per surface unit, $\sigma$ is Stefan-Boltzmann constant, $\varepsilon$ is the surface emissivity, $T_{e}$ and $T_{a}$ are the emission and absorption surface temperatures, respectively. To achieve the heat balance, the total heat transfer can be concluded by using Eq. 3 .

$\mathrm{Q}_{\mathrm{T}}=\mathrm{Q}_{\text {cond }}+\mathrm{Q}_{\text {conv }}+\mathrm{Q}_{\mathrm{r}}$

In Eq. $3 \mathrm{Q}_{\mathrm{T}}$, $\mathrm{Q}_{\text {cond }}$, $\mathrm{Q}_{\text {conv }}$, and $\mathrm{Q}_{\mathrm{r}}$ represent total, conduction, convection, and radiation heat transfer, respectively. Convection heat transfer is calculated using Newton's cooling law. Total heat gain/loss results in the temperature change of the receiver as:

$$
\mathrm{Q}_{\mathrm{T}}=\mathrm{mC}_{\mathrm{p}}\left(\mathrm{T}_{\mathrm{f}}-\mathrm{T}_{\mathrm{i}}\right)
$$

where $C_{p}, T_{f}$, and $T i$ are heat capacity, initial temperature, and final temperature of the receiver, respectively.

The heat gain of the receiver occurs at the bottom surface by radiation. The reflected rays concentrate at the focal plane of the receiver (shown in Fig.1) and absorbed, while other surfaces of the receiver cool down the whole body by radiation and convection mechanisms. $\mathrm{ZrB}_{2}$ as a UHTC is used for receiver material because of its high melting point and acceptable thermal conductivity [59]. The radiation emissivity for the material has assumed to be 0.8 . To model incidence radiation from the sun, and its reflection from the concentrator, the Geometry Optics module of Comsol Multiphysics has been used.

\section{Results}

The present work aims to simulate the optical behavior of a parabolic collector to generate heat in its focal point. As a clean source of energy, concentrated rays can generate high temperatures that can be employed to melt the metals or used as a heat source in the sintering of ceramics. The ray trajectories emanating from the parabolic solar collector are

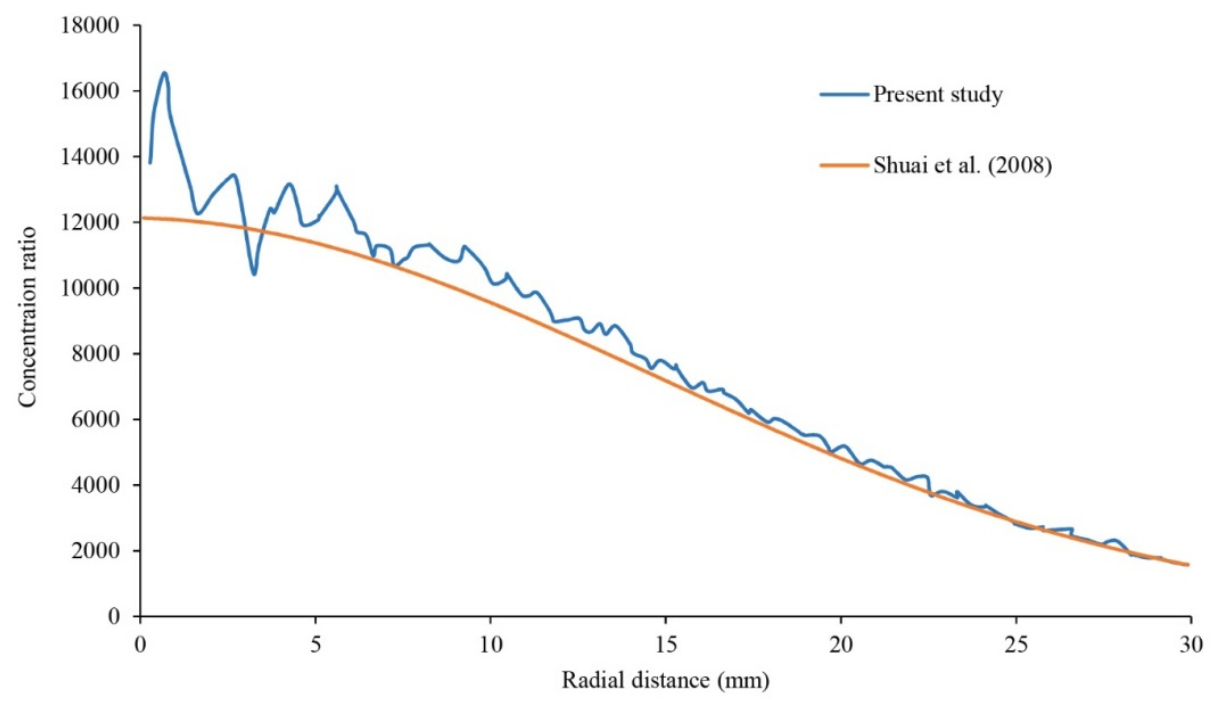

Fig. 6. The comparison between the azimuthally averaged concentration ratios to the result of Shuai et al. [33]. 

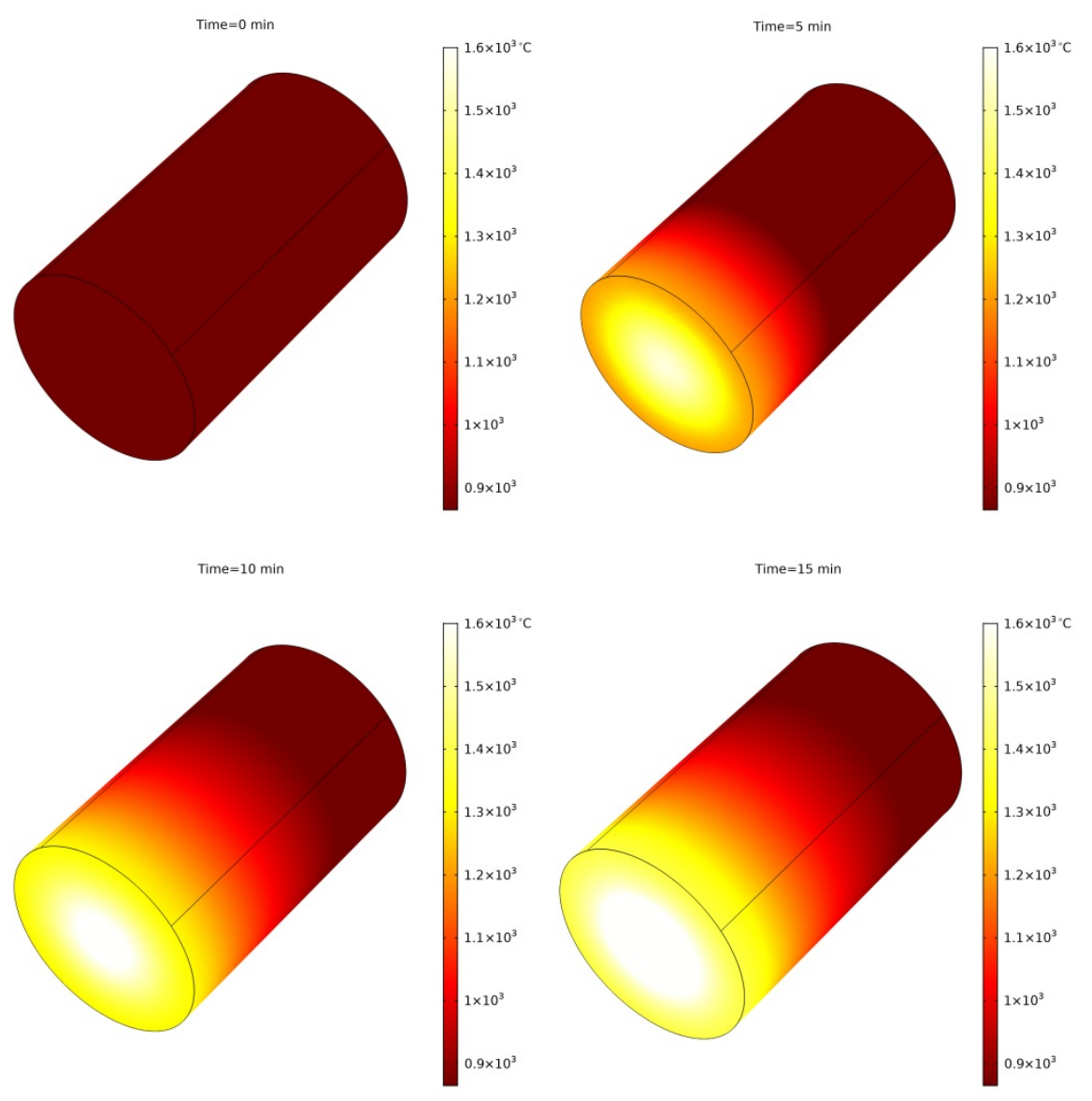

Fig. 7. Temperature contours versus time in $\mathrm{ZrB}_{2}$ made receiver.

shown in Fig. 3. To avoid a tangled picture, only some of the trajectories were selected. The reflected rays were absorbed by a receiver located at the focal plane.
In the case of an ideal parabolic reflector with completely smooth surfaces, that resulted heat flux on the surface of the receiver is shown in Fig. 4. In this case, the solar limb darkening has been neglected. Fig.

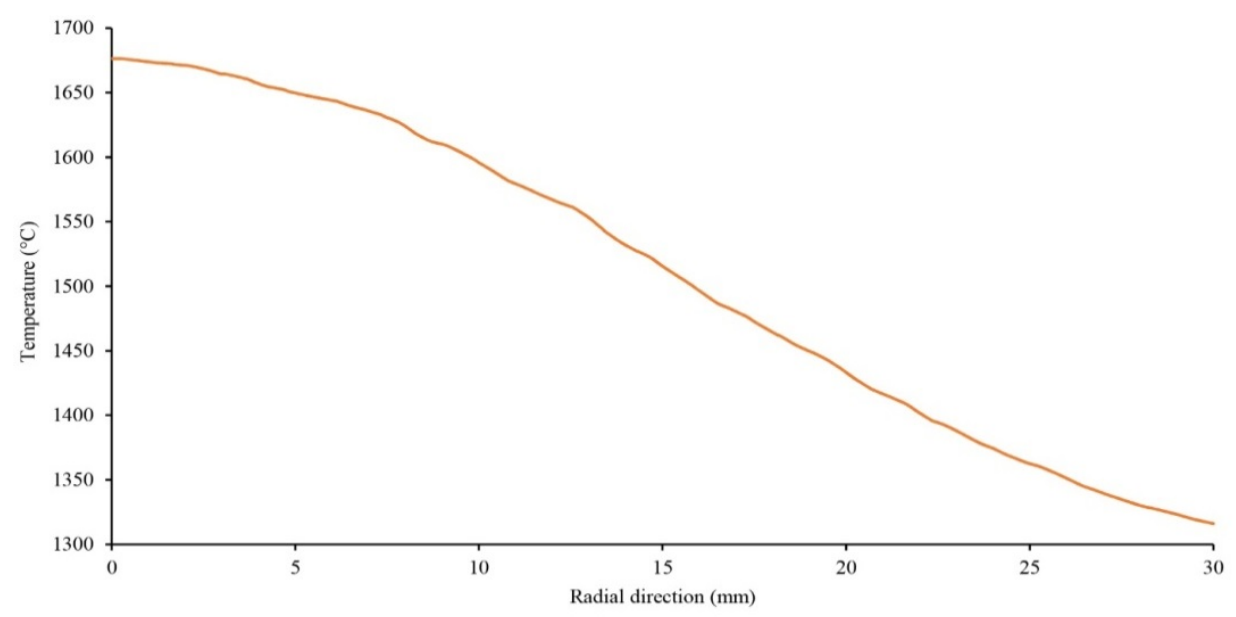

Fig. 8. Radial temperature distribution in receiving boundary at $\mathrm{t}=15 \mathrm{~min}$. 


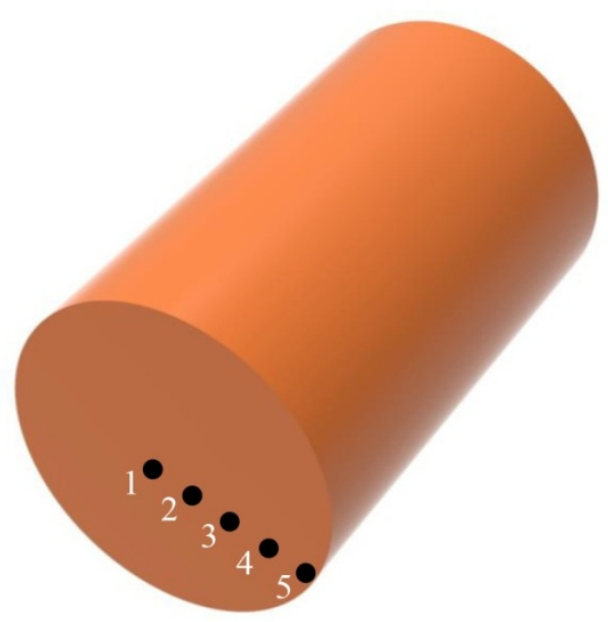

Fig. 9. The location of the selected points along the radius of the sample at the lower surface.

4 indicates high heat fluxes on the receiver surfaces especially in the regions close to the center of the sample. The average heat flux value is assumed $6.86 \times 10^{6} \mathrm{~W} / \mathrm{m}^{2}$ for the city of Ardabil, Iran, while a maximum heat flux of $36 \times 10^{6} \mathrm{~W} / \mathrm{m}^{2}$ is obtained at the center of the surface.

However, the real reflectors are not ideally smoothed and a substantial number of rays miss the receiver and continue to propagate, which results in reduced efficiency of the cavity receiver. Fig. 5 shows the collected heat flux in the focal plane at the real condition. In this case, the effects of surface roughness, absorption, and solar limb darkening are taken into account. Compared to Fig. 4 the heat flux contour of Fig.
5 is much more widespread which results in considerably reduced heat flux at the focal plane.

The azimuthally averaged concentration ratio is compared with the data reported by Shuai et al. [33] in Fig. 6. In this case, a good agreement is observable which validates the applied numerical method.

The collected rays on the focal point can be used as a powerful heat source. The high heat fluxes cause high temperatures at the focal point of the collector. Here, $\mathrm{ZrB}_{2}$ as an ultrahigh temperature ceramic is employed in the focal plane of the collector, which can be used in different applications such as melting furnace, sintering die, hydrogen generation bed, etc. The real condition of the ray's collection was employed to warm up the lower part of the receiver. The receiver is located in the ambient temperature and cools down by the natural convection and radiation mechanisms. The temperature distribution versus time is shown in Fig 7.

The sample is heated at the lower surface and the heat diffuses through the body by conduction mechanism. On the other hand, the heat dissipates from all surfaces of the body by natural convection and radiation. As time passes, the received heat from the bottom surface conducts to the upper layers of the sample, and consequently the temperature increases in all points of the receiver. Fig. 7 shows a considerable temperature value in the sample so that a maximum value of $1680{ }^{\circ} \mathrm{C}$ is obtained at $\mathrm{t}=15 \mathrm{~min}$. The obtained values show the potential of solar collectors in generating high temperatures. Since metals deform or oxidize in these temperatures, ultrahigh temperature ceramics are good candidates for this harsh working condition. The maximum temperature is located at the center of the receiving boundary and a reduction in temperature is observed toward the edges of the sample. The boundaries of the sample are subjected to convective and radiative heat losses. The radial temperature distribution in the receiving boundary is shown in Fig. 8 at the time $\mathrm{t}=$ $15 \mathrm{~min}$.

To investigate the radial temperature variation versus time, four points

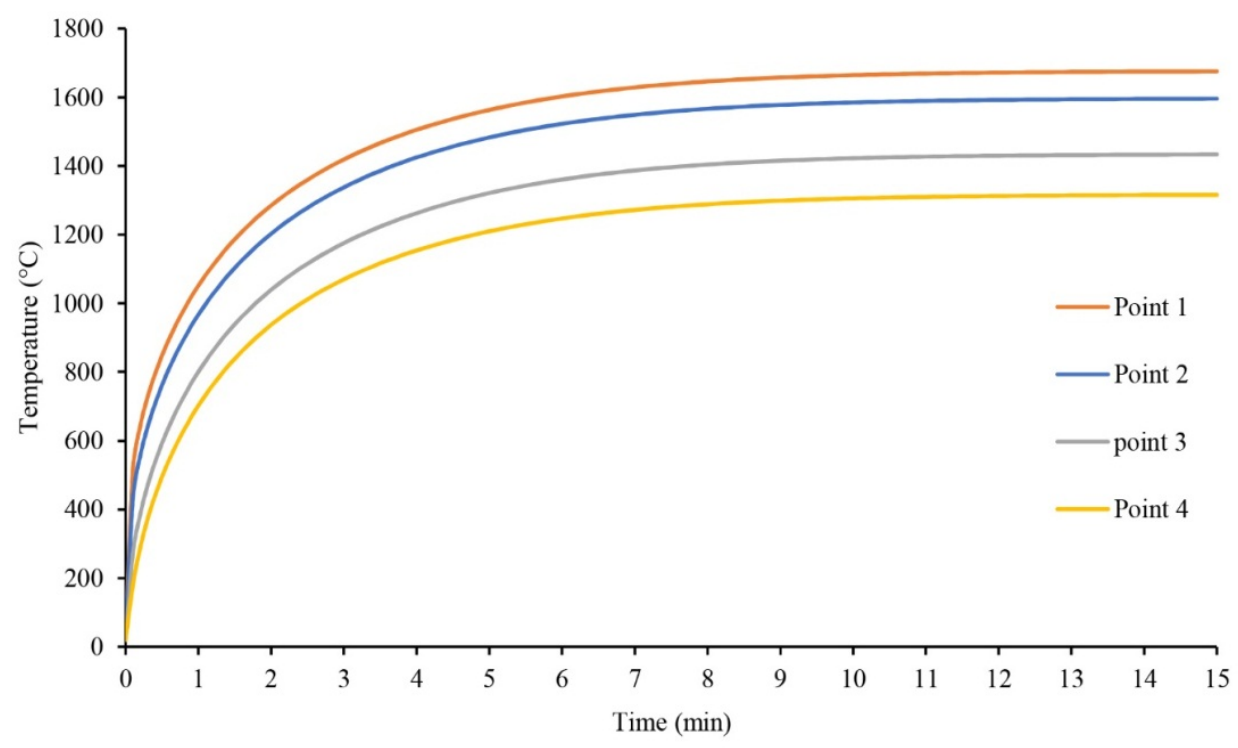

Fig. 10. Temperature variation versus time at the different radial points. 


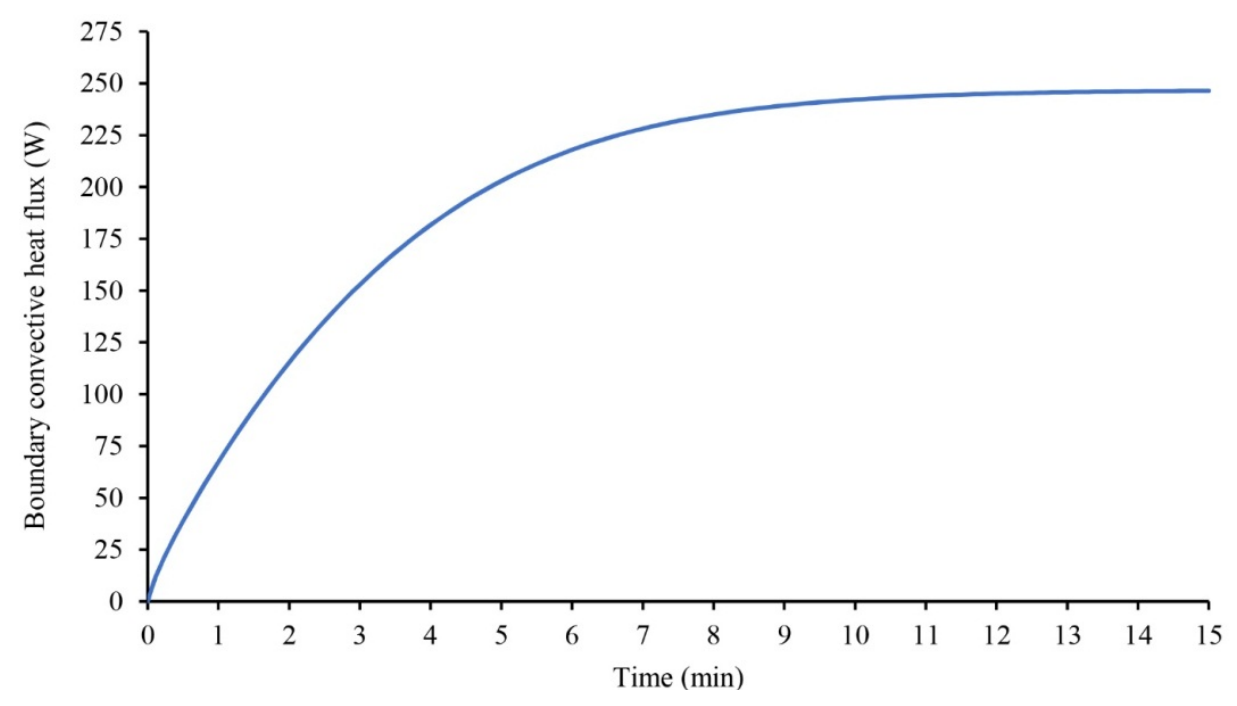

Fig. 11. Convective heat loss from the sample walls.

in the receiving boundary were selected as shown in Fig. 9. The temperature variation versus time in these points is depicted in Fig. 10. The temperature of all four points increases sharply at the beginning and by time, the slope of the plots diminishes, and the temperature reaches its constant value, which is a steady-state condition. It worth noting that the applied heat from the collector is balanced by the convection and radiation heat losses from the sidewalls of the sample. The convective heat transfer from all boundaries is given in Fig. 11.

The convective heat transfer shows an increasing behavior versus time. This comes back to the increased temperature of the sample. Considering Newton's cooling law, the convective heat transfer is directly proportional to the temperature difference between the hot wall and the ambient temperature. As time passes, the temperature difference between the sample walls and surrounding air increases and result in increased convective heat transfer.

The radiative heat transfer from the sample walls also plays an important role in heat dissipation from the sample and reaching a steady-state condition. The radiative heat loss is given in Fig. 12 versus time. Based on Eq. 2 the radiative heat transfer is a function of the 4th power of the temperature. As the sample temperature increases, the radiative heat transfer increases considerably. The radiative heat transfer shows a sharp behavior at the first time steps, however, the slope of the curve decreases as time passes. This can be attributed to the balance between the applied heat fluxes and heat losses. As a result, as the temperature approaches a constant value, the radiative heat transfer reaches a constant value, as well.

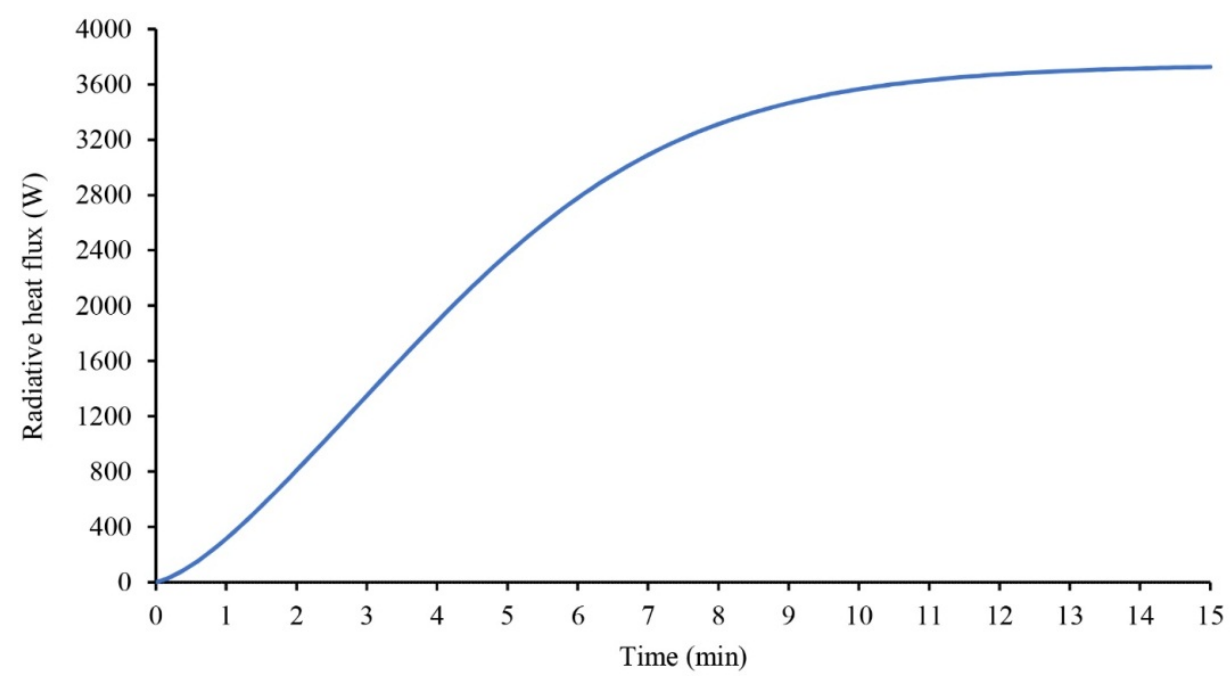

Fig. 12. The radiative heat transfer from the sample walls versus time. 


\section{Conclusions}

Using renewable energies is growing recently as an alternative energy source for fossil fuels. Radiation heat from the sun can be absorbed by different materials. However, to increase the final temperature of the receivers, using a concentrator is inevitable. In the present work concentrated rays are absorbed by a $\mathrm{ZrB}_{2}$-made receiver and the heat transfer was investigated. The governing equations are solved using the finite element method and the results as temperature contours and ray traces were introduced. The results showed that the absorbed heat can generate high temperatures up to $1680{ }^{\circ} \mathrm{C}$ in the receiver. $\mathrm{ZrB}_{2}$ as a UHTC can tolerate such high temperatures because of its high strength and melting point. Finally, it can be admitted that UHTCs are a good alternative for solar receivers.

\section{References}

[1] T. Gholizadeh, M. Vajdi, F. Mohammadkhani, Thermodynamic and thermoeconomic analysis of basic and modified power generation systems fueled by biogas, Energy Convers. Manag. 181 (2019) 463475.

[2] H. Azariyan, M. Vajdi, H. Rostamnejad Takleh, Assessment of a high-performance geothermal-based multigeneration system for production of power, cooling, and hydrogen: Thermodynamic and exergoeconomic evaluation, Energy Convers. Manag. 236 (2021) 113970.

[3] F. Sadegh Moghanlou, S. Noorzadeh, M. Ataei, M. Vajdi, M. Shahedi Asl, E. Esmaeilzadeh, Experimental investigation of heat transfer and pressure drop in a minichannel heat sink using Al2O3 and TiO2-water nanofluids, J. Brazilian Soc. Mech. Sci. Eng. 42 (2020) 315 .

[4] M. Ataei, F. Sadegh Moghanlou, S. Noorzadeh, M. Vajdi, M. Shahedi Asl, Heat transfer and flow characteristics of hybrid A12O3/TiO2-water nanofluid in a minichannel heat sink, Heat Mass Transf. 56 (2020) 2757-2767.

[5] S. Noorzadeh, F. Sadegh Moghanlou, M. Vajdi, M. Ataei, Thermal conductivity, viscosity and heat transfer process in nanofluids: A critical review, J. Compos. Compd. (2020).

[6] M. Namazizadeh, R. Haghighi khoshkhoo, F. Joda, Effect of Air Gap on thermohydraulic performance of finned tube bundles, Therm. Sci. Eng. Prog. 20 (2020) 100687.

[7] K. Lovegrove, G. Burgess, J. Pye, A new 500m2 paraboloidal dish solar concentrator, Sol. Energy. 85 (2011) 620-626.

[8] W. Lipiński, J.H. Davidson, S. Haussener, J.F. Klausner, A.M. Mehdizadeh, J. Petrasch, A. Steinfeld, L. Venstrom, Review of Heat Transfer Research for Solar Thermochemical Applications, J. Therm. Sci. Eng. Appl. 5 (2013).

[9] Z. Şen, Solar energy in progress and future research trends, Prog. Energy Combust. Sci. 30 (2004) 367-416.

[10] D.Y. Goswami, S. Vijayaraghavan, S. Lu, G. Tamm, New and emerging developments in solar energy, Sol. Energy. 76 (2004) 3343.

[11] T. Tsoutsos, V. Gekas, K. Marketaki, Technical and economical evaluation of solar thermal power generation, Renew. Energy. 28 (2003) 873-886

[12] S.A. Kalogirou, Solar thermal collectors and applications, Prog. Energy Combust. Sci. 30 (2004) 231-295.

[13] J.C.G. Pereira, J. Rodríguez, J.C. Fernandes, L.G. Rosa, Homogeneous Flux Distribution in High-Flux Solar Furnaces, Energies. 13 (2020) 433.

[14] D. Fernández-González, I. Ruiz-Bustinza, C. González-Gasca, J. Piñuela Noval, J. Mochón-Castaños, J. Sancho-Gorostiaga, L.F. Verdeja, Concentrated solar energy applications in materials science and metallurgy, Sol. Energy. 170 (2018) 520-540.
[15] F. Sadegh Moghanlou, M. Vajdi, M. Sakkaki, S. Azizi, Effect of graphite die geometry on energy consumption during spark plasma sintering of zirconium diboride, Synth. Sinter. 1 (2021) 54-61.

[16] F. Wang, R. Lin, B. Liu, H. Tan, Y. Shuai, Optical efficiency analysis of cylindrical cavity receiver with bottom surface convex, Sol. Energy. 90 (2013) 195-204.

[17] M. Wang, K. Siddiqui, The impact of geometrical parameters on the thermal performance of a solar receiver of dish-type concentrated solar energy system, Renew. Energy. 35 (2010) 2501-2513.

[18] Z.D. Cheng, Y.L. He, B.C. Du, K. Wang, Q. Liang, Geometric optimization on optical performance of parabolic trough solar collector systems using particle swarm optimization algorithm, Appl. Energy. 148 (2015) 282-293.

[19] C.A. Asselineau, J. Zapata, J. Pye, Geometrical Shape Optimization of a Cavity Receiver Using Coupled Radiative and Hydrodynamic Modeling, Energy Procedia. 69 (2015) 279-288.

[20] S. Li, G. Xu, X. Luo, Y. Quan, Y. Ge, Optical performance of a solar dish concentrator/receiver system: Influence of geometrical and surface properties of cavity receiver, Energy. 113 (2016) 95-107.

[21] X. Wei, Z. Lu, W. Yu, Z. Wang, A new code for the design and analysis of the heliostat field layout for power tower system, Sol. Energy. 84 (2010) 685-690.

[22] B.J. Hathaway, W. Lipiński, J.H. Davidson, Heat Transfer in a Solar Cavity Receiver: Design Considerations, Numer. Heat Transf. Part A Appl. 62 (2012) 445-461.

[23] H. Li, W. Huang, F. Huang, P. Hu, Z. Chen, Optical analysis and optimization of parabolic dish solar concentrator with a cavity receiver, Sol. Energy. 92 (2013) 288-297.

[24] A. Sánchez-González, D. Santana, Solar flux distribution on central receivers: A projection method from analytic function, Renew. Energy. 74 (2015) 576-587.

[25] S. Skouri, A. Ben Haj Ali, S. Bouadila, S. Ben Nasrallah, Optical qualification of a solar parabolic concentrator using photogrammetry technique, Energy. 90 (2015) 403-416.

[26] D. Riveros-Rosas, J. Herrera-Vázquez, C.A. Pérez-Rábago, C.A. Arancibia-Bulnes, S. Vázquez-Montiel, M. Sánchez-González, F. Granados-Agustín, O.A. Jaramillo, C.A. Estrada, Optical design of a high radiative flux solar furnace for Mexico, Sol. Energy. 84 (2010) 792-800.

[27] R. Abbas, M.J. Montes, M. Piera, J.M. Martínez-Val, Solar radiation concentration features in Linear Fresnel Reflector arrays, Energy Convers. Manag. 54 (2012) 133-144.

[28] Y. Qiu, Y.L. He, Z.D. Cheng, K. Wang, Study on optical and thermal performance of a linear Fresnel solar reflector using molten salt as HTF with MCRT and FVM methods, Appl. Energy. 146 (2015) 162-173.

[29] Q. Mao, Y. Shuai, Y. Yuan, Study on radiation flux of the receiver with a parabolic solar concentrator system, Energy Convers. Manag. 84 (2014) 1-6.

[30] X. Chen, X. Xia, X. Dong, G. Dai, Integrated analysis on the volumetric absorption characteristics and optical performance for a porous media receiver, Energy Convers. Manag. 105 (2015) 562 569.

[31] C.A. Asselineau, J. Zapata, J. Pye, Integration of Monte-Carlo ray tracing with a stochastic optimisation method: application to the design of solar receiver geometry, Opt. Express. 23 (2015) A437.

[32] N. León, H. Aguayo, H. García, A. Anaya, Computer Aided Optimization/Innovation of Passive Tracking Solar Concentration Fresnel Lens. (2011) 57-70.

[33] Y. Shuai, X.L. Xia, H.P. Tan, Radiation performance of dish solar concentrator/cavity receiver systems, Sol. Energy. 82 (2008) 13-21.

[34] W.T. Xie, Y.J. Dai, R.Z. Wang, Numerical and experimental analysis of a point focus solar collector using high concentration imaging PMMA Fresnel lens, Energy Convers. Manag. 52 (2011) 2417-2426.

[35] C. Zou, Y. Zhang, H. Feng, Q. Falcoz, P. Neveu, W. Gao, C. Zhang, Effects of geometric parameters on thermal performance for a 
cylindrical solar receiver using a 3D numerical model, Energy Convers. Manag. 149 (2017) 293-302.

[36] R.E. Hogan, R.B. Diver, W.B. Stine, Comparison of a Cavity Solar Receiver Numerical Model and Experimental Data, J. Sol. Energy Eng. 112 (1990) 183-190.

[37] W. Wang, H. Xu, B. Laumert, T. Strand, An inverse design method for a cavity receiver used in solar dish Brayton system, Sol. Energy. 110 (2014) 745-755.

[38] R. Beltran, N. Velazquez, A.C. Espericueta, D. Sauceda, G. Perez, Mathematical model for the study and design of a solar dish collector with cavity receiver for its application in Stirling engines, J. Mech. Sci. Technol. 26 (2012) 3311-3321.

[39] W. Wang, B. Laumert, H. Xu, T. Strand, Conjugate heat transfer analysis of an impinging receiver design for a dish-Brayton system, Sol. Energy. 119 (2015) 298-309.

[40] G. Xu, Y. Wang, Y. Quan, H. Li, S. Li, G. Song, W. Gao, Design and characteristics of a novel tapered tube bundle receiver for hightemperature solar dish system, Appl. Therm. Eng. 91 (2015) 791799.

[41] R. Senthil, M. Cheralathan, Effect of the phase change material in a solar receiver on thermal performance of parabolic dish collector, Therm. Sci. 21 (2017) 2803-2812.

[42] E. Sani, S. Failla, D. Sciti, Dark alumina for novel solar receivers, Scr. Mater. 176 (2020) 58-62.

[43] M. Vajdi, F. Sadegh Moghanlou, E. Ranjbarpour Niari, M. Shahedi Asl, M. Shokouhimehr, Heat transfer and pressure drop in a $\mathrm{ZrB} 2$ microchannel heat sink: A numerical approach, Ceram. Int. 46 (2020) $1730-1735$.

[44]A. Sabahi Namini, A. Motallebzadeh, B. Nayebi, M. Shahedi Asl, M. Azadbeh, Microstructure-mechanical properties correlation in spark plasma sintered Ti- 4.8 wt $\%$ TiB2 composites, Mater. Chem. Phys. 223 (2019) 789-796.

[45] Y. Zhou, H. Xiang, Z. Feng, Z. Li, General Trends in Electronic Structure, Stability, Chemical Bonding and Mechanical Properties of Ultrahigh Temperature Ceramics TMB2 $(\mathrm{TM}=$ transition metal), $\mathrm{J}$. Mater. Sci. Technol. 31 (2015) 285-294.

[46] R.G. Munro, Material properties of titanium diboride, J. Res. Natl. Inst. Stand. Technol. 105 (2000) 709.

[47] B. Basu, G.B. Raju, A.K. Suri, Processing and properties of monolithic TiB2 based materials, Int. Mater. Rev. 51 (2006) 352374.

[48] S. Nekahi, K. Vaferi, M. Vajdi, F. Sadegh Moghanlou, M. Shahedi Asl, M. Shokouhimehr, A numerical approach to the heat transfer and thermal stress in a gas turbine stator blade made of HfB2, Ceram. Int. 45 (2019) 24060-24069.

[49] F. Adibpur, S.A. Tayebifard, M. Zakeri, M. Shahedi Asl, Spark plasma sintering of quadruplet $\mathrm{ZrB} 2-\mathrm{SiC}-\mathrm{ZrC}-\mathrm{Cf}$ composites, Ceram. Int. 46 (2020) 156-164.

[50] M. Shahedi Asl, B. Nayebi, A. Motallebzadeh, M. Shokouhimehr, Nanoindentation and nanostructural characterization of $\mathrm{ZrB} 2-\mathrm{SiC}$ composite doped with graphite nano-flakes, Compos. Part B Eng. 175 (2019) 107153.

[51] Z. Ahmadi, M. Zakeri, A. Habibi-Yangjeh, M. Shahedi Asl, A novel ZrB2-C3N4 composite with improved mechanical properties, Ceram. Int. 45 (2019) 21512-21519.

[52] H. Kinoshita, S. Otani, S. Kamiyama, H. Amano, I. Akasaki, J. Suda, H. Matsunami, Zirconium Diboride (0001) as an Electrically Conductive Lattice-Matched Substrate for Gallium Nitride, Jpn. J. Appl. Phys. 40 (2001) 1280-1282.

[53] F. Sadegh Moghanlou, M. Vajdi, J. Sha, A. Motallebzadeh, M. Shokouhimehr, M. Shahedi Asl, A numerical approach to the heat transfer in monolithic and $\mathrm{SiC}$ reinforced $\mathrm{HfB} 2, \mathrm{ZrB} 2$ and $\mathrm{TiB} 2$ ceramic cutting tools, Ceram. Int. 45 (2019) 15892-15897.

[54] H. Xiang, J. Wang, Y. Zhou, Theoretical predictions on intrinsic lattice thermal conductivity of ZrB2, J. Eur. Ceram. Soc. 39 (2019) 2982-2988.

[55] M.A. Arie, A.H. Shooshtari, S.V. Dessiatoun, E. Al-Hajri, M.M. Ohadi, Numerical modeling and thermal optimization of a singlephase flow manifold-microchannel plate heat exchanger, Int. J. Heat Mass Transf. 81 (2015) 478-489.

[56] Z. Hajati, F. Sadegh Moghanlou, M. Vajdi, E. Razavi, S. Matin, Fluid Structure Interaction of blood flow around a vein valve, BioImpacts. 10 (2020) 169-175.

[57]M. Vajdi, F. Sadegh Moghanlou, F. Sharifianjazi, M. Shahedi Asl, M. Shokouhimehr, A review on the Comsol Multiphysics studies of heat transfer in advanced ceramics, J. Compos. Compd. 2 (2020) 35-44.

[58] J. Diatta, G. Antou, N. Pradeilles, A. Maître, Numerical modeling of spark plasma sintering-Discussion on densification mechanism identification and generated porosity gradients, J. Eur. Ceram. Soc. 37 (2017) 4849-4860.

[59] F. Sadegh Moghanlou, M. Vajdi, A. Motallebzadeh, J. Sha, M. Shokouhimehr, M. Shahedi Asl, Numerical analyses of heat transfer and thermal stress in a $\mathrm{ZrB} 2$ gas turbine stator blade, Ceram. Int. 45 (2019) 17742-17750. 